\title{
Obtaining Frozen Semen of Bulls with Superior Qualitative Parameters
}

\author{
Constantin GĂVAN \\ Agricultural Research and Development Station Șimnic - Craiova, România \\ *corresponding author: scda_simnic@yahoo.com
}

Bulletin UASVM Animal Science and Biotechnologies 77(1)/ 2020

Print ISSN 1843-5262; Electronic ISSN 1843-536X

DOI:10.15835/buasvmcn-asb: 0001.20

\begin{abstract}
Sperm is a zootechnical production that is harvested, controlled, processed and used, within a well-defined technological stream.Biotechnological intensification of breeding to increase birth and prolificity in zootechnics requires complex control of spermatic production on scientific bases in accordance with current legislation and compliance with national and international standards.

In this regard, complex control of sperm production, regardless of its origin, is required by performing ordinary and special spermograms. In the modern technological flow of artificial cattle insemination, processing by dilution is an essential step with obvious zooeconomic implications, because it greatly increases the number of usable doses obtained from an ejaculate, increases the possibility of insemination a much bigger number by larger females, directly contributing to increased male selection pressure.
\end{abstract}

Keywords: semen, fecundity, harvest.

\section{Introduction}

The major objective of practicing artificial insemination is the genetic improvement of the herd by the intensive and rational use of the male breeders of high zootechnical value on a very large herd of females. In calves the semen obtained from an ejaculate can be divided into hundreds of doses with which so many females can be inseminated. Improving the techniques of dilution and preservation of semen by freezing has made it possible to increase the load of females on bulls, used in artificial insemination. In this paper the focus will be on the improvement of processing, preservation technologies other than those described by Drume C (1987) in "Technology for the production of frozen semen". Obtaining conventional semen with higher quality parameters is a major concern for improving its sampling and processing methods. By improving the classical methods of processing, freezing, storage of bull semen, the cryobiological rejection is not greater than $7 \%$, the microbial load is within the limits provided by the European norms in the field and implicitly the most important decision to increase fertility in following its use in artificial insemination in cows.

Sperm is a zootechnical production that is harvested, controlled, processed and used within a well-defined technological flow. Cryopreservation of semen offers the possibility of indeterminate storage of semen in liquid nitrogen with acceptable fertility rates after thawing.

The process of intensifying breeding in order to increase birth rate and prolificacy in animal husbandry involves the complex control of sperm production on a scientific basis in accordance 
with the legislation in force and compliance with national and international standards.

In this regard, complex control of sperm production, regardless of its origin, is required by performing ordinary and special spermograms. In the modern technological flow of artificial cattle insemination, processing by dilution is an essential step with obvious zooeconomic implications, because it greatly increases the number of usable doses obtained from an ejaculate, increases the possibility of insemination a much bigger number by larger females, directly contributing to increased male selection pressure.

\section{Materials and methods}

A number of 29 bulls from different breeds from Semtest Craiova were studied. These bulls were harvested and the semen was processed according to the classical method within 3 years. Comparatively, the same bulls whose semen was processed according to the improved classical method are described as follows:

The stages of processing the bull sperm in order to obtain frozen semen are:

1. Harvesting of raw semen;

2. Appreciation of the semen collected, with the determination of the main spermatic indicators;

3. Determining the degree of dilution, the total volume and the number of doses for each ejaculate;

4. Dilution of raw semen;

5. Distribution of diluted semen in P.V.C tubes;

6. Closing of P.V.C .;

7. Thermal and glycerin balancing of the diluted semen;

8. Freezing of diluted and balanced semen;

9. Technical quality control of frozen semen;

10. Storage of frozen semen;

11. Delivery of frozen semen.

The actual harvesting of semen:

After performing sexual stimulation, the bull is allowed to perform the jump.

The semen is harvested using the artificial vagina, which consists of: 1) the body of the vagina, 2) the vaginal shirt, 3) the tap for filling with water and blowing air. Within this proposed technology, the semen is collected in a special conical bag over which another protection bag is attached which ensures good thermal insulation, the air between the two bags is bad thermal conductor and thus thermal protection is ensured compared to the temperature of the harvesting room.

The advantages of this method of collection are very important:

- the semen collected does not leave the collection

bag until it is sucked into the straw;

- the contact of the semen with the atmosphere of the processing laboratory is avoided (avoiding overloading with germs).

Since the sperm is diluted directly in the harvesting bag, it is avoided to transfer it to various containers (avoiding the overloading of germs from the glassware specific to the old technology):

- the integrity of the sperm is maintained by the fact that no transfer is made from one container to another for various dilution, aspiration, etc. operations. as in the old classical technologies;

- suction of semen in sequins is done directly from the collection bag after dilution;

- this method eliminates the use of glassware specific to the classical technology for processing semen, which requires a lot of labor through the operations of washing, sterilization, etc.

\section{Appreciation of raw semen:}

The quantitative and qualitative assessment of the semen material is carried out immediately after harvesting, following: the volume, the color, the smell, the presence of foreign bodies, the sowing, the movement energy of the waves, the mobility and the concentration.

The macroscopic examination is performed directly in the harvesting bag and consists in the appreciation of the following aspects: volume, color, smell and presence of foreign bodies. Macroscopic examination of the semen harvested

Ejaculate volume:

It is evaluated in the weighing bag by means of a precision scale that expresses the quantity of sperm harvested in grams. By assimilation taking into account the specific weight of the sperm it can be approximated that one gram of sperm represents approximately $1 \mathrm{ml}$ of sperm. On average the ejaculates at the bull are 5-7 $\mathrm{ml}$ with limits between 2-15ml (Bara). During processing, ejaculate with a volume of $2 \mathrm{ml}$ in young bulls and $3 \mathrm{ml}$ in adult bulls is allowed.

The color of the semen: Normal semen looks milky white to creamy white. It presents a 
relatively uniform opacity, which indicates a high concentration in sperm.

The smell of semen: The semen has a characteristic smell of freshly boiled and shaved bone.

Microscopic examination of semen: Appreciation of density, wave energy and mobility of the sperm are evaluated according to the classical method under the microscope under isothermal conditions $\left(37-38^{\circ} \mathrm{C}\right)$, using the platinum heater. These examinations are done immediately after the ejaculate is collected, the blades, blades, pipettes are kept at the thermostat at a temperature of 37 $38^{\circ} \mathrm{C}$. The appreciation of the semen is compulsory both in the free drop for the density and energy of the waves, as well as in the lamella for the mobility of the sperm in the microscopic field. The drop that is placed under the lamella will not exceed $3 \mathrm{~mm}$ in diameter. 2-3 microscopic areas will be examined at magnification power 200 (ocular10 $x$ objective 20). For the examination in the drop drop, the magnifying power $100(10 \times 10)$ will be used.

The wave displacement energy expresses the intensity of sperm movement in the microscopic field. In the microscopic field, a greater or lesser number of sperm cells will be observed, that is, a greater or lesser tenth of them. From this point of view, the examined semen can be appreciated and classified in the following categories: dense, medium, rare and oligospermia.

The estimation of the percentage of moving sperm is made microscopically on an arbitrary scale of grades from 1 to 0.1 . The concentration represents the number of sperm in a milliliter of crude semen and can be performed by several methods: hemocytometric, photocolorimetric or electronic.

Determining the degree of dilution, total volume and number of doses:

The dilution of the semen aims to obtain several doses, with a sufficient number of movable sperm, to ensure a normal conception rate. The internal standard of quality of frozen semen after thawing recommended in Romanian farms provides for the supply of a minimum of 7 million mobile sperm per dose in the frozen semen dose. To achieve this goal, in the formula for determining the degree of dilution the total number of sperm per dose, before freezing, will be approximately 25 million.
Calculation of the number of doses/ejaculate processed:

The calculation of the number of doses/ ejaculate processed is done by the relation:

Nr. estimated doses/ejaculated $\frac{\mathrm{V}_{\mathrm{T}}}{0.21}$ doses $=$

in which: $\mathrm{V}_{\mathrm{T}}$ = the total volume of the ejaculate; $0.21=$ the volume of semen aspirated in the tube P.V.C.

\section{Dilution of semen:}

Diluents are added to the sperm to protect it during cryopreservation and to provide nutrients as a source of energy, buffer against $\mathrm{PH}$ modifications, provide adequate physiological osmotic pressure, electrolyte concentration and prevent bacterial growth. In the last 65 years the cryoprotective environment has been constantly revised and improved. Philips showed for the first time the value of adding egg yolk as a cryoprotective component in freezing sperm. Low density lipoprotein fraction (LDL) has been shown to play an important role in protecting sperm. Recent studies and research support the idea that LDL interacts with major seminal plasma proteins and this interaction appears to be crucial for sperm protection (Swanard and Clifford). In 1949, Polge et al. they made a discovery by showing that the use of glycerol in the diluent offers protection of cells at low temperatures. The discovery of the protective properties of egg yolk and glycerol helped to develop diluents based on synthetic lysosomes and cholesterol-laden cyclodextrins that provide better protection for sperm, during cryopreservation which resulted in increased survival rates after thawing. Supplementation with antioxidants such as methionine, carnitine and inositol prior to the cryopreservation process has been shown to protect the integrity of DNA during freezing. Most bovine sperm diluents contain antibiotics to reduce the rate of bacterial overgrowth and its detrimental effect on semen quality, knowing that bacteria are present in the genitals and reproductive organs of bulls and are difficult to avoid even with the most hygienic sampling and processing procedures. 
Table. 1. Analysis of the results regarding the cryobiological rejection index according to the working technology at the bulls collected at SEMTEST Craiova

\begin{tabular}{|c|c|c|c|c|c|c|}
\hline \multirow{2}{*}{ Working technology } & \multirow{2}{*}{ The year } & \multirow{2}{*}{$\mathrm{n}$} & \multicolumn{4}{|c|}{ Calculated statistical parameters } \\
\hline & & & $\mathrm{x}$ & $\pm S x$ & $\mathrm{~s}$ & V\% \\
\hline \multirow{4}{*}{ Classic technology } & $\mathrm{I}$ & 11 & 25.60 & 10.40 & 34.50 & 134.70 \\
\hline & I & 9 & 16.90 & 4.21 & 12.63 & 74.73 \\
\hline & III & 9 & 13.60 & 2.80 & 8.40 & 61.90 \\
\hline & TOTAL & 29 & 19.17 & 3.64 & 19.60 & 102.29 \\
\hline \multirow{4}{*}{ Improved technology } & I & 10 & 13.00 & 3.15 & 9.96 & 102.29 \\
\hline & II & 9 & 14.90 & 3.30 & 9.90 & 66.60 \\
\hline & III & 9 & 8.60 & 2.40 & 7.20 & 119.40 \\
\hline & TOTAL & 28 & 12.19 & 1.70 & 9.05 & 74.27 \\
\hline
\end{tabular}

$\mathrm{n}=$ number of bulls under study

$\mathrm{x}=$ cryobiological receipt percentage

The dilution of the semen is done immediately after the completion of the quantitative and qualitative assessment of the ejaculate.

The dilution will be performed in a single step with ready-made synthetic diluents prepared with the trade name OPTIDIL or ANDROMED and bidistilled water. The components mix well with a sterile glass wand in a sterile glass container of large size, with a capacity of $1500 \mathrm{ml}$, at $30^{\circ} \mathrm{C}$. The dilution takes place directly in the collection bag, which, after the completion of the quantitative and qualitative assessment, is welded using a polyethylene foil welding device, and then with a sterile scissors one of the welded corners of the bag is cut on an area of about $1.5 \mathrm{~cm}$.

The clamping clip is provided with a device for adjusting the diluent flow rate, which is to flow over the sperm in the bag.

For a good homogenization of the diluent with the raw semen, the collection bag together with the silicone tube and the funnel, is mounted on an apparatus provided with an oscillating pad, which by means of horizontal movements ensures a very good mix between the two environments. The mixture is made at room temperature, at about $20-25^{\circ} \mathrm{C}$, and the diluent must flow dropwise so that the raw sperm comes into contact gradually with the diluent. After dilution, the diluted semen is distributed in P.V.C. tubes of $0.25 \mathrm{ml}$.

The actual volume with semen of the tube is $0.21 \mathrm{ml}$.

The distribution of the diluted semen in 0.25 $\mathrm{ml}$ tubes it is realized with the help of a suction and closing system of the straw based on ultrasound. The automatic filling system inhales the semen directly from the collection bag in which the dilution was carried out. Suction of the material in the straw is done through a disposable silicone tube, then through a 4-needle system the material is suctioned using a vacuum pump. The closing of the straws is carried out by an ultrasound system that ensures the perfect welding of the straw.

The individualization of the straws is done by ink jet and the following data are entered: the code number of the bull or the registration number, the name of the bull, the breed of the bull, the date of freezing (batch), the code of the harvesting unit, negative IBR.

Thermal and glycerin balancing of the diluted semen:

The tubes with diluted semen are placed on special metal ramps (which will also be used in the freezing process). Ramps where the tubes with diluted semen are displayed and then place in the refrigerator box, specially built to ensure a temperature of $+4-5^{\circ} \mathrm{C}$, where stored for a minimum of 2 hours, this helps to reduce the metabolic rate of the sperm by minimizing the damage caused by the heat shock.

Freezing of semen:

The freezing of the tubes is carried out in liquid nitrogen vapors, at a temperature of $-135-140^{\circ} \mathrm{C}$, in automatic freezers, programmable, which offers the option to accurately cover the temperature 
inside the cooling chamber and to program the graph of the freezing curve. For a good freeze the straws must be placed on one row on the racks in order to ensure a uniform cooling rate inside the straws. After an exposure time of 12-14 minutes the semen is frozen.

Technical quality control of frozen semen:

Qualitative verification of frozen semen is done 24 to 48 hours after freezing. For each batch, at least one straw is thawed for the assessment of post-freezing motility and concentration. The examination can be done according to the classical or electronic method, according to the CASA method, which can provide information on sperm concentration, morphology, viability and fragmentation rates of thawed sperm DNA. This evaluation system provides information on subtle changes in sperm movement that cannot be identified by conventional analysis. The parameters usually examined by the CASA method are the motility, speed, linearity and movement of the sperm as they progress along their trajectory. For semen of high genetic value can be examined according to the flow cytometrymethod: evaluation of the status of the acrosome, mitochondrial activity that has the role of generating energetic substances for sperm cell motility, as well as the integrity of DNA by analyzing the structure of the sperm chromatin. The DNA fragmentation index is correlated with the fertility of the bull (CK.Vincent col).

Storage of frozen semen:

After checking and approving the quality, the frozen semen is stored in large capacity containers. The level of liquid nitrogen in the tanks should be monitored regularly and supplemented when necessary. When handling the material in the tank, care must be taken that the transfer containers are kept as low as possible in the tank to maintain the temperature of the straws at a constant of $-196^{\circ} \mathrm{C}$.

\section{Results and discussions}

The sperm harvesting, the macroscopic and microscopic appreciation of the sperm, the dilution, the suction in the tubes of the semen is done directly from the bag of harvesting process which ensures the integrity of the sperm. By reducing the number of transfers from one container to another, some trauma to the sperm will be avoided (tail breaking etc.). It eliminates the possibility of overloading with exogenous microorganisms from the equipment and glassware used in other technologies. Also, the contact of the semen during processing with the laboratory environment is eliminated. The frozen semen of bull obtained after this method has been shown to have superior qualitative parameters, the sperm progressivity improves by $10 \%$ compared to the classical methods, it is reduced by $5-8 \%$ cryobiological receipt after thawing of the semen (BARA M.).

According to this technology, the genetic center Semtest Craiova produces, stores and delivers approximately 300,000 doses of semen from different bull breeds annually. The fertility of cows sown with this material has been shown to be $10-15 \%$ higher compared to the classical method described by DRUME C., 1987.

\section{Conclusion}

The cryobiological rejection rates of frozen semen according to the method described were 12.19 (with a range of $8.60 \%-14.90 \%$ ) compared to the classical technology which was $19.17 \%$ (with a range between 13\% - 25.60\%).

The processing of semen according to this method has the following advantages:

- Good thermal protection of the sperm during the harvest is ensured;

- By using synthetic diluents, semen is produced in which the dilution is done in a single fraction;

- By simplifying the technology, the personnel expenses are reduced;

- The analysis of semen by CASA methods and flow cytometry obtain predictive information regarding the quality and fertility of the semen.

\section{References}

1. Bara SS, Teză de doctorat: Performanța productivă și reproductivă a raselor de taur de carne importate în România, USAMV Cluj-Napoca, 2012.

2. Barth AD, Bowman B, Bowman PA (1988). Determination of the best practical method of thawing bovine semen. Canadian Veterinary Journal, 29, 366-369.

3. Biniova Z, Stadnik L, Dolezalova M, Duchacek J (2018). Effect of thawing method on bull sperm survival in ejaculates frozen in $4 \mathrm{ml}$ and $8 \mathrm{ml}$ volumes. Czech J. Anim. Sci., 63, $399-407$.

4. Vincent P., Underwood S.L., Dolbec C., Bouchard N., Kroetsch T. Blondin P. - Bovine semen quality control in 
artificial insemination centers. Anim. Reprod., vol. 9, n. 3,153-165, 2012.

5. Dolezalova M, Stadnik L, Biniova Z, Duchacek J, Stupka R (2016): Equilibration and freezing interactions affecting bull sperm characteristics after thawing. Czech Journal of Animal Science, 61, 515-525.

6. Drume C (1987). Tehnologia de producere a materialului seminal congelat. Norme tehnice de calitate și control, Revista „SEMTEST", Norme tehnice interne, București.

7. Bara M. Cercetări privind optimizarea biotehnologiei de recoltare şi prelucrare a spermei de taur, Bucharest -Teza de doctorat, 2003, USAMV Bucuresti.

8. Saragusty J, Gaciuta H, Pettit MT (2007). Directional freezing of equine semen in large volumes. Reproduction in Domestic Animals, 42, 610-615.

9. Stoica A, Dumitrescu I, Bara M, Drăguț P (2017) Researches over Cryobiological Spermograms at Bull.
Reproduction and Psychology, Animal Sci. Conference, BALNIMAL CON.

10. Swanand S, Shipley CF (2014). Cryopreservation of semen, Bovine Reproduction, 71, $662-670$.

11. Thurston LM, Watson PF, Holt WV (2002). Semen cryopreservation: A genetic explanation for species and individual variation? Cryo Letters, 23, 255-262.

12. Underwood SL, Bathgate R, Maxwell WMC, Evans G (2009). In vitro characteristics of frozen-thawed, sex sorted bull sperm after refreezing or incubation at 15 or $37^{\circ} \mathrm{C}$. Theriogenology, 72, 1001-1008.

13. Underwood SL, Bathgate R, Maxwell WMC, Evans G (2010): Birth of offspring after artificial insemination of heifers with frozen-thawed, sex-sorted, re-frozen-thawed bull sperm. Animal Reproduction Science, 118, 171-175. 